\title{
Major upper limb replantation: a review of clinical pearls
}

\author{
Margaret Luthringer, Margaret Dalena, Haripriya S. Ayyala \\ Division of Plastic and Reconstructive Surgery, Rutgers-New Jersey Medical School, Newark, NJ 08873, USA.
}

Correspondence to: Dr. Haripriya S. Ayyala, Division of Plastic and Reconstructive Surgery, Rutgers-New Jersey Medical School, 140 Bergen St, Suite E1620, Newark, NJ 08873, USA. E-mail: ha289@njms.rutgers.edu

\begin{abstract}
How to cite this article: Luthringer M, Dalena M, Ayyala HS. Major upper limb replantation: a review of clinical pearls. Plast
\end{abstract} Aesthet Res 2020;7:42. http://dx.doi.org/10.20517/2347-9264.2020.35

Received: 11 Mar 2020 First Decision: 22 May 2020 Revised: 3 Jul 2020 Accepted: 20 Jul 2020 Published: 15 Aug 2020

Academic Editor: A Thione Copy Editor: Cai-Hong Wang Production Editor: Jing Yu

\begin{abstract}
Replantation of major segments of the extremities can be a formidable task. Adequate debridement of crushed tissues is a prerequisite for successful major limb replantation. This article serves to elucidate the important situational and patient factors a surgeon must consider when choosing between replantation or revision amputation for upper limb salvage.
\end{abstract}

Keywords: Limb salvage, major limb replantation, microsurgery, upper extremity, reconstruction

\section{INTRODUCTION}

Since Malt and McKhan's first successful upper extremity replantation in 1962, ever-evolving surgical techniques have redefined outcomes for patients with these life-altering injuries ${ }^{[1]}$. Still, these cases remain a challenge for surgeons who must make difficult decisions regarding replant candidacy and surgical options. In 2005, approximately 170,000 people in the United States were living with a wrist-proximal upper extremity amputation. Young males are predominantly affected; trauma remains the leading cause of injury in this group ${ }^{[2]}$. Though prosthetic options for upper extremity amputation have significantly improved in recent years, rejection rates of devices have been described to be as high as $30 \%{ }^{[3]}$. Further, post-operative functionality can be unpredictable. Upper limb replantation continues to yield better overall subjective results over revision amputation ${ }^{[3]}$. This article serves to review the important situational and patient factors a surgeon must consider when choosing between replantation or revision amputation for 
upper limb salvage. We also emphasize technical points that may lead to successful upper extremity major limb replantation.

\section{EVALUATION AND ASSESSMENT}

Surgeons considering upper extremity replantation must take into account the injury's devastating effect on patient quality of life, functionality, and possible financial burden ${ }^{[4,5]}$. Despite the profound nature of this decision process, few substantiated algorithms delineating replantation versus revision amputation exist in the current literature. Märdian et al. ${ }^{[5]}$ proposed an algorithm that took into account injury pattern, patient risk factors, ischemia time, and contamination. Larson et al ${ }^{[6]}$ expounded upon variables that were significantly associated with choosing replantation: severity of systemic conditions, mechanism and level of injury, ischemia time, and patient motivation comprised the foremost imperative factors involved in management choice. Regardless, all algorithms should include a full initial patient evaluation per conventional trauma standards. After going through the advanced trauma life support protocol, a thorough exam, appropriate studies, and radiographic images of the proximal appendage and amputated segment should be included in the initial assessment. Patients suffering high acuity systemic trauma may demonstrate compromised ability for wound healing which is incompatible with replantation. Life threatening injuries may absolutely preclude patients from undergoing long operations with sustained general anesthesia ${ }^{[6,7]}$. Larson et al. ${ }^{[6]}$ described in his retrospective study, spanning 11 years with 62 upper extremity amputation patients, a significant association with the choice of revision amputation and an Injury Severity Score of 16 or greater, indicating severe trauma. Further, those higher acuity patients who did undergo replantation were more likely to experience replant failure ${ }^{[6]}$.

The mechanism and level of injury plays a large role in anticipating the salvage probability of soft tissue structures at amputation sites. Sharp or penetrating injuries, especially "guillotine" amputations, demonstrate less extensive damage to sharply divided soft tissues. These injuries are associated with significantly higher rates of attempted replantation over crush or avulsion events ${ }^{[6]}$. Injuries that are distally located may also encourage replantation attempts. On the other hand, proximal injuries may be prone to increased effects of ischemia as more muscle mass and neuronal tissue are devoid of perfusion. Additionally, this tissue is subsequently exposed to greater oxidative stress and reperfusion injury that can sabotage microsurgical replantation efforts ${ }^{[6,8-10]}$. Therefore, the upper extremity amputation injury must be considered when constructing an operative plan.

Furthermore, a close relationship between the surgeon and occupational therapist is invaluable to obtain optimal function outcomes. Frequent communication of plans allows for real-time feedback, rehabilitative protocol revision when needed, and can increase a patient's faith in the treatment plan. Having a trusted and reliable team of therapists available is vital when evaluating a patient for successful replantation. It is also critical the patient be evaluated holistically to ensure appropriate candidacy for replantation. Patients with injuries caused by multiple self-harm attempts may discourage replantation attempts unless postoperative mental health care and constant monitoring are in place. When possible, the surgeon must assess the patient's occupation, physical demands, and motivation to endure a long and arduous rehabilitative course.

\section{PROGNOSTIC FACTORS FOR UPPER EXTREMITY LIMB VIABILITY}

One of the most crucial variables affecting limb salvage after replantation is the ischemia time of the amputated segment. Replantation for wrist-proximal amputations should be attempted before $12 \mathrm{~h}$ of cold ischemia time or $6 \mathrm{~h}$ of warm ischemia time ${ }^{[11]}$. Prolonged warm ischemia time is particularly associated with increased changes in cellular metabolism of susceptible muscle tissue. Damaging oxidative stress renders the muscles dysfunctional, increases vessel permeability, and predisposes the patient to reperfusion syndrome ${ }^{[1]]}$. Emergency personnel should be instructed to wrap the amputated extremity in gauze and 
cool it on ice as soon as possible ${ }^{[1]}$. Inflow and outflow shunts may be utilized in anticipation of long transport times. A large catheter may be used between a single intact vein if present; arterial flow is reestablished with a carotid shunt or intravascular catheter ${ }^{[1]}$. A prospective study of 186 complete upper extremity amputations by Waikakul et al ${ }^{[8]}$ described post-operative reperfusion syndrome in $5.4 \%$ of patients. Though not statistically significant, patients with a total ischemic time between 6-8 h had a higher rate of failure when compared to those with 0-6 h. Tantry et al. ${ }^{[9]}$ presented a series of 14 upper extremity amputation patients, all of whom had total limb ischemia times of more than 6 h. The 4 patients who developed intraoperative/early post-operative events all had 8 or more hours of total ischemia. Reperfusion events observed included hypotension, bronchospasm, acidosis, and atrial fibrillation.

The severity, mechanism, and level of injury to the upper extremity is associated with the probability of successful limb salvage. Severity of the injury can manifest in several ways; large crush injuries may damage multiple functional muscle units, portending a poor prognosis for post-operative function. These extensive crush injuries are also typically plagued with severe tissue contamination. Meticulous debridement, vigorous irrigation, and antimicrobial therapy can mitigate the deleterious effects of initial contamination on functional outcomes after replantation ${ }^{[9]}$. A crush injury may be debrided in order to convert it to a sharp injury, facilitating ease and functional healing of the repair. Avulsion events may themselves obviate functional recovery, as axonal and vascular damage to nefariously proximal levels may underlie seemingly distal amputations. In fact, rotary machine injuries portend the worse outcomes of all injury types ${ }^{[12]}$. Clean guillotine injuries are more amenable to successful replantation and subsequent function ${ }^{[6,8]}$. Replantation of more distal amputations tends to be associated with better function post-operatively. This may be in part due to the increased length of axonal regeneration required for higher injuries ${ }^{[10]}$.

Most patient demographic variables have little bearing on replantation success, with gender and age showing no significant difference in salvage rates. History of smoking may be associated with higher rates of failed replantation efforts ${ }^{[8]}$.

\section{PEARLS FOR UPPER EXTREMITY REPLANTATION}

\section{Debridement and soft tissue injury}

While some studies use severe contamination as a contraindication to replantation surgery, contamination has no significant association with adverse events or limb survival after thorough irrigation and debridement ${ }^{[0,9,12]}$. Aggressive debridement combined with appropriate antibiotic coverage decreases the risk of post-operative infections and is imperative in the management of upper extremity injuries ${ }^{[6]}$. Meticulous inspection of the amputated segment is crucial and can be done prior to the operation itself to maximize efficiency ${ }^{[13]}$. Exposed vascular structures should be carefully examined under loupe magnification or the operating microscope. Signs of vessel damage, such as a "red line" or corkscrew "ribbon sign", can signify traction injury and separation of intima from media. Any anastomosis attempted in regions afflicted with this type of damage are prone to thrombosis ${ }^{[14,15]}$. Thus, with prior inspection of the amputated segment, the zone of injury of the amputated limb can be properly estimated and the need for vein grafts and a safe location for neurovascular anastomoses can be considered before incising the proximal stump. Any ischemic or contaminated tissue of the segment can be sharply debrided at this time. Aggressive excision of any tissue that appears compromised is advocated, as soft tissue complications are the main cause of failure in major limb replantation ${ }^{[16]}$.

Tissue sepsis and necrosis can lead to neurovascular exposure and desiccation and may incite an inflammatory cascade that promulgates a thrombogenic environment ${ }^{[16]}$. Sharp excision and copious wound irrigation with an antibiotic solution are encouraged; pulse lavage or high-pressure irrigation is not often recommended as this can push fluid and bacteria into the tissues causing significant edema and deep infection ${ }^{[17]}$. As stated previously, ischemic time should be at the forefront of the surgeon's mind during this 
process. Shunting should be utilized as necessary during the debridement process, which may preclude separate preparation of the amputated segment. As serial debridement may be required until definitive coverage, temporary dressings are often utilized to keep the wounds clean and to prevent desiccation ${ }^{[18]}$.

\section{Bone shortening}

In addition to thorough debridement of soft tissue, bone shortening is a technique that is highly advantageous in replantation surgeries. Bone shortening is critical for removing any devitalized bone and other necrotic structures, thereby promoting bony union and decreasing the risk of osteomyelitis, deep infections, and necrosis ${ }^{[19]}$. Additionally, bone shortening presents the opportunity to convert crush and avulsion injuries to "guillotine" type injuries, facilitating reconstruction by converting damaged nerves and vessels to clean and vitalized structures suitable for coaptation and anastomosis ${ }^{[19,20]}$. Bone shortening may also allow physicians to avoid vein and nerve grafts. Shortening also decreases tension on anastomoses and skin repair and reduces soft tissue defect size, decreasing the need for flap coverage ${ }^{[19,21,22]}$. The radius and ulna may tolerate from $2.5 \mathrm{~cm}$ to $5.0 \mathrm{~cm}$ of shortening and the humerus may tolerate up to $8 \mathrm{~cm}$ of shortening with acceptable functional results ${ }^{[13]}$. The benefits of bone shortening, including decreased risk of wound infections and replantation failure, outweigh the risks of a shortened limb with potentially diminished functionality. The literature has demonstrated that shortening within the aforementioned parameters has a negligible effect on subsequent function ${ }^{[15,19]}$. Appropriate tensioning of the involved muscles and tendons and meticulous nerve repair, with or without the use of transfers, is paramount in this setting. When possible, the patient should be informed of the expected cosmetic implications of arm length discrepancy as well as the arduous post-operative rehabilitative course to gain back strength and range.

\section{Ectopic banking}

Though rarely employed, the amputated segment may be temporarily banked if a patient's critical condition or complex injury at the proximal stump precludes immediate replantation. Godina et al ${ }^{[23]}$ first described this method in 1986 for the ectopic implantation and subsequent replantation of an amputated hand. This technique allows for expeditious temporary salvage of the amputated segment as only skin and vascular reconstruction need be undertaken ${ }^{[24]}$. Recipient vessel site choice is crucial and must be well outside the zone of injury. Though Godina initially favored the thoracodorsal artery at the axilla as the recipient vessel in banking, microsurgeons have generally shifted their preference to the contralateral distal radial artery. This allows for ease of serial debridement and physical therapy of the ectopic segment. Further, the contralateral radial artery can be reconstructed with a vein graft at the same time as the replant, decreasing operative time ${ }^{[24]}$. The banked segment should be replanted as soon as possible, preferably within 1-2 weeks. This allows for a more stable position for the segment and for nerves and tendons to be repaired rapidly ${ }^{[24,25]}$. When the ectopic segment is harvested, the previous anastomosis should be preserved. A significant amount of the length of the recipient vessel should be taken to avoid the zone of injury during replantation ${ }^{[24]}$.

\section{Secondary procedures}

Secondary procedures are commonplace following upper extremity limb replantation. Fufa et al. ${ }^{[26]}$ described a series of patients that underwent an average of three secondary procedures. Axelrod et al. ${ }^{[19]}$ demonstrated an average of 4.2 secondary procedures per patient. Prior to any attempts, patients should understand the arduous road of replantation, including the need for multiple reconstructive surgeries to improve functional results. Secondary procedures commonly include soft tissue coverage with vascularized flaps, free functioning muscle transfer, tenolysis, tendon transfer, and nerve grafts ${ }^{[6,19,26,27]}$. Certain secondary procedures are more common depending on the location of the replantation as well as the mechanism of amputation sustained.

Distal and wrist level amputations commonly require tenolysis to improve range of motion, while proximal-level amputations often require soft tissue coverage due to high intensity mechanisms of injury 
typically sustained at this amputation level ${ }^{[27]}$. Soft tissue coverage may include skin grafting or vascularized tissue transfer; however, flaps are typically preferred as skin grafts may cause contracture limiting muscle excursion $^{[26,27]}$.

Free functioning muscle transfer is an important secondary procedure commonly performed in avulsion injuries of the forearm and elbow. Avulsion injuries of this area severely disrupt the long flexor and extensor tendons of the hand. These tendons may be too damaged for direct repair and essential musculature may be removed after thorough debridement. When tendon transfers are not an option, the replanted limb can suffer severely diminished functional capacity, requiring free functional neurotized muscle transfer ${ }^{[26,27]}$.

\section{Anticoagulation}

Intraoperative and post-operative anticoagulation therapy are controversial topics among microsurgeons performing replantation. Ideally, the goals of anticoagulation for microvascular anastomoses are to prevent thrombosis and improve vascular patency by decreasing platelet function, increasing blood flow or decreasing blood viscosity, and counteracting the effects of thrombin on platelets and fibrinogen ${ }^{[28,29]}$. However, these effects may also lead to undue complications such as hemorrhage or hematoma which may further compromise the vascular anastomoses within replants ${ }^{[28,30]}$.

We recommend a post-operative regimen similar to other free tissue transfer procedures, consisting of low molecular weight heparin (LMWH) at prophylactic deep vein thrombosis dosing starting on postoperative day 1 for the duration of the patient's inpatient stay as well as $325 \mathrm{mg}$ of Aspirin for 1 month post-operatively. Other commonly used anticoagulants include heparin and dextran; however, LMWH is preferred over unfractionated heparin as LMWH has better defined therapeutic and prophylactic dosages and carries a decreased risk of heparin induced thrombocytopenia ${ }^{[2]}$. Dextran decreases platelet activity and increases blood volume which thereby decreases blood viscosity; however, it is largely avoided in the current literature as it may induce serious complications such as anaphylaxis, pulmonary edema, adult respiratory distress syndrome, cerebral edema, acute renal failure, or congestive heart failure ${ }^{[31]}$. Additionally, some microvascular surgeons performing free flaps and digit and limb replantation choose to not use any pre-, intra-, or post-operative anticoagulation while still reporting favorable results ${ }^{[32]}$. Ultimately, the controversy surrounding this topic remains and prospective, randomized controlled trials are required to define recommendations for anticoagulation therapy following major upper limb replantation.

\section{REPLANTATION VS. AMPUTATION WITH AND WITHOUT PROSTHETIC FITTING}

Patients who undergo successful replantation report significantly improved outcomes and satisfaction as compared to patients who undergo revision amputation with prosthetic rehabilitation ${ }^{[33]}$. However, prosthetic technology, including targeted muscle reinnervation, myoelectric prostheses and osseointegration, continues to advance and holds the potential for superior limb dexterity and functionality ${ }^{[33,34]}$. Limb replantation is currently superior to revision amputation and prosthetic rehabilitation. As prothesis technology improves, future research will be required into this topic.

\section{Cost-effectiveness analysis}

As compared to revision amputation, upper extremity replantation is associated with longer rehabilitation, increased time to return to work, and increased costs overall ${ }^{[12]}$. However, upper extremity replantation has been demonstrated to be a cost-effective approach as compared to revision amputation, particularly for highly motivated patients and patients of younger age at time of injury ${ }^{[35]}$.

Other than patient reported outcomes and functional scoring systems, there is no definitive cost-benefit analysis of major upper extremity replantation as compared to revision amputation with prosthetic fitting. 
Patients' baseline functional status, occupation, type of injury sustained, and type of prosthetic used is unique to each patient, rendering a definitive cost benefit analysis difficult to produce ${ }^{[7]}$. Initial costs of limb replantation exceed the cost of revision amputations ${ }^{[33,35]}$. However, advanced prostheses such as those involving targeted muscle reinnervation and myoelectric prosthesis can be incredibly expensive ${ }^{[12,33]}$. While pain and difficulty of prosthetic use are some of the most common reasons for prothesis disuse by patients, financial burden is another commonly cited reason for prothesis abandonment ${ }^{[33]}$. Intensive rehabilitation is required for both replantation and prosthesis use in order to regain the most function ${ }^{[36]}$.

\section{CONCLUSION}

Upper extremity amputations are devastating injuries. However, with appropriate management strategies in place, major limb replantation is a potentially life changing option for those who have suffered these injuries. While major limb replantation is not a viable option for every patient, the authors emphasize the importance of appropriate patient selection and surgical management strategies, including aggressive soft tissue and bone debridement in order to improve outcomes in these injuries.

\section{DECLARATIONS}

\section{Acknowledgments}

The authors would like to acknowledge Dr. Ramazi Datiashvili for his expert advice.

\section{Authors' contributions}

Wrote the manuscript: Luthringer M, Dalena M

Approved the final version of the manuscript: Luthringer M, Dalena M, Ayyala HS

Conceived the study: Ayyala HS

Provided critical revisions that are important for intellectual content: Ayyala HS

Supervision and project administration: Ayyala HS

Contributed equally to this article: Luthringer M, Dalena M, Ayyala HS

\section{Availability of data and materials}

Not applicable.

\section{Financial support and sponsorship}

None.

\section{Conflicts of interest}

All authors declared that there are no conflicts of interest.

\section{Ethical approval and consent to participate}

Not applicable.

\section{Consent for publication}

Not applicable.

\section{Copyright}

(c) The Author(s) 2020.

\section{REFERENCES}

1. Hanel DP, Chin SH. Wrist level and proximal-upper extremity replantation. Hand Clin 2007;23:13-21.

2. Ziegler-Graham K, MacKenzie EJ, Ephraim PL, Travison TG, Brookmeyer R. Estimating the prevalence of limb loss in the United States: 2005 to 2050. Arch Phys Med Rehabil 2008;89:422-9. 
3. Yueh JH, Bar-Meir ED, Liao EC, Lee BT. Major limb replantation. Eplasty 2011;11:ic1.

4. Prucz RB, Friedrich JB. Upper extremity replantation: current concepts. Plast Reconstr Surg 2014;133:333-42.

5. Märdian S, Krapohl BD, Roffeis J, Disch AC, Schaser KD, et al. Complete major amputation of the upper extremity: early results and initial treatment algorithm. J Trauma Acute Care Surg 2015;78:586-93.

6. Larson JV, Kung TA, Cederna PS, Sears ED, Urbanchek MG, et al. Clinical factors associated with replantation after traumatic major upper extremity amputation. Plast Reconstr Surg 2013;132:911-9.

7. Chung KC, Alderman AK. Replantation of the upper extremity: indications and outcomes. J Am Soc Surg Hand 2002;2:78-94.

8. Waikakul S, Vanadurongwan V, Unnanuntana A. Prognostic factors for major limb re-implantation at both immediate and long-term follow-up. J Bone Joint Surg Br 1998;80:1024-30.

9. Tantry TP, Kadam D, Shenoy SP, Bhandary S, Adappa KK. Perioperative evaluation and outcomes of major limb replantations with ischemia periods of more than 6 hours. J Reconstr Microsurg 2013;29:165-72.

10. Atkins SE, Winterton RIS, Kay SP. (v) Upper limb amputations: where, when and how to replant. Curr Orthopaed 2008;22:31-41.

11. Carden DL, Korthuis RJ. Mechanisms of postischemic vascular dysfunction in skeletal muscle: implications for therapeutic intervention. Microcirc Endothelium Lymphatics 1989;5:277-98.

12. Wolfe VM, Wang AA. Replantation of the upper extremity: current concepts. J Am Acad Orthop Surg 2015;23:373-81.

13. Woo SH. Practical tips to improve efficiency and success in upper limb replantation. Plast Reconstr Surg 2019;144:878e-911.

14. Pet MA, Ko JH. Indications for replantation and revascularization in the hand. Hand Clin 2019;35:119-30.

15. Maricevich M, Carlsen B, Mardini S, Moran S. Upper extremity and digital replantation. Hand (N Y) 2011;6:356-63.

16. Cavadas PC. Salvage of replanted upper extremities with major soft-tissue complications. J Plast Reconstr Aesthet Surg 2007;60:769-75.

17. Dzwierzynski WW. Replantation and revascularization. In: Neligan P, Chang J, editors. Plastic Surgery. Vol 6. 3 ed. Elsevier; 2017.

18. Ahuja NK, Datiashvili RO. Biobrane in the management of critical microsurgical wounds of the upper extremity. Microsurgery 2012;32:196-200.

19. Axelrod TS, Buchler U. Severe complex injuries to the upper extremity: revascularization and replantation. J Hand Surg Am 1991;16:574-84.

20. Daoutis NK, Gerostathopoulos N, Efstathopoulos D, Misitzis D, Bouchlis G, et al. Major amputation of the upper extremity. Functional results after replantation/revascularization in 47 cases. Acta Orthop Scand Suppl 1995;264:7-8.

21. Battiston B, Tos P, Clemente A, Pontini I. Actualities in big segments replantation surgery. J Plast Reconstr Aesthet Surg 2007;60:849-55.

22. Leclère FM, Mathys L, Juon B, Franz T, Unglaub F, et al. Macroreplantations of the upper extremity: a series of 11 patients. Arch Orthop Trauma Surg 2012;132:1797-805.

23. Godina M, Bajec J, Baraga A. Salvage of the mutilated upper extremity with temporary ectopic implantation of the undamaged part. Plast Reconstr Surg 1986;78:295-9.

24. Higgins JP. Ectopic banking of amputated parts: a clinical review. J Hand Surg Am 2011;36:1868-76.

25. Li J, Ni GH, Guo Z, Fan HB, Cong R, et al. Salvage of amputated thumbs by temporary ectopic implantation. Microsurgery 2008;28:559-64.

26. Fufa D, Lin CH, Lin YT, Hsu CC, Chuang CC, et al. Secondary reconstructive surgery following major upper extremity replantation. Plast Reconstr Surg 2014;134:713-20.

27. Venkatramani H, Bhardwaj P, Sabapathy SR. Role of free functioning muscle transfer in improving the functional outcomes following replantation of crush avulsion amputations of the forearm. Injury 2019;50 Suppl 5:S105-10.

28. Askari M, Fisher C, Weniger FG, Bidic S, Lee WP. Anticoagulation therapy in microsurgery: a review. J Hand Surg Am 2006;31:836-46.

29. Ketchum LD. Pharmacological alterations in the clotting mechanism: use in microvascular surgery. J Hand Surg Am 1978;3:407-15.

30. Hemker HC, Béguin S, Kakkar VV. Can the haemorrhagic component of heparin be identified? Or an attempt at clean thinking on a dirty drug. Haemostasis 1996;26:117-26.

31. Levin LS, Cooper EO. Clinical use of anticoagulants following replantation surgery. J Hand Surg Am 2008;33:1437-9.

32. Veravuthipakorn L, Veravuthipakorn A. Microsurgical free flap and replantation without antithrombotic agents. J Med Assoc Thai 2004;87:665-9.

33. Pet MA, Morrison SD, Mack JS, Sears ED, Wright T, et al. Comparison of patient-reported outcomes after traumatic upper extremity amputation: replantation versus prosthetic rehabilitation. Injury 2016;47:2783-8.

34. Pierrie SN, Gaston RG, Loeffler BJ. Current concepts in upper-extremity amputation. J Hand Surg Am 2018;43:657-67.

35. Yoon AP, Mahajani T, Hutton DW, Chung KC; Finger Replantation and Amputation Challenges in Assessing Impairment, Satisfaction, and Effectiveness (FRANCHISE) Group. Cost-effectiveness of finger replantation compared with revision amputation. JAMA Netw Open 2019;2:e1916509.

36. Cancio JM, Ikeda AJ, Barnicott SL, Childers WL, Alderete JF, et al. Upper extremity amputation and prosthetics care across the active duty military and veteran populations. Phys Med Rehabil Clin N Am 2019;30:73-87. 